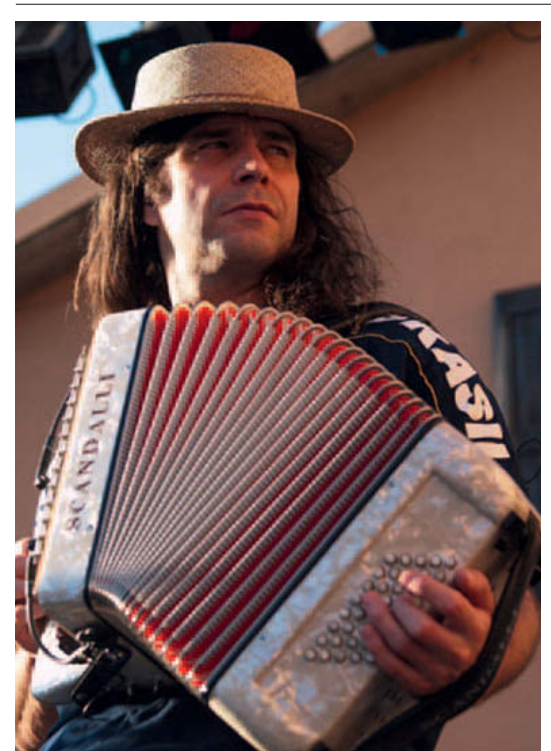

DOCUMENTA (13)

\section{Nach Kassel zur Kunst!}

Nur alle fünf Jahre findet die Veranstaltung statt und alleine das macht die documenta in Kassel zu einem besonderen Ereignis. Aber natürlich ist die Momentaufnahme der zeitgenössischen bildenden Kunst die Hauptattraktion. Heuer ist es wieder soweit! Also verwandelt sich die knapp 200.000 Einwohnerstadt in Hessen mit den traditionellen Ausstellungsstätten und Kunst im gesamten Stadtbild 100 Tage lang in die Welthauptstadt der zeitgenössischen Kunst. Ein Ereignis der Sonderklasse!

Schon im Vorfeld lässt sich seit April des Vorjahres im Internet das Projekt 100 Notizen - 100 Gedanken mitverfolgen, das unterschiedlichste Positionen von eingeladenen Künstlern zeigt - und in Broschürenform auch einzeln erhältlich ist. Herzstück des Ausstellungsgeschehens, das 1955 ins Leben gerufen wurde, ist das Fridericianum, dazu gibt es die documentaHalle, als Freiluftausstellungsräume den Friedrichsplatz und die Karlsaue und verschiedene andere Museen der Stadt oder auch das Schloss Wilhelmshöhe. Als künstlerische Leiterin der dOCUMENTA (13) fungiert die amerikanisch-italienische Autorin und Kunsthistorikern Carolyn Christov-Bakargiev, die mit ihren Mitarbeitern einen-bewusst offenen-Prozess der Entstehung der dOCUMENTA (13) gestaltet. Es geht um die Spiegelung der Vielfalt der (Kunst)-Welt. Ab 9. Juni lässt sich das Ergebis hautnah in Kassel erleben.

Informationen: http://d13.documenta.de

\section{AKKORDEON}

\section{Rund um die Welt}

International ist das Akkordeon ja schon lange in den vielfältigsten Stilen und Anwendergruppen unterwegs. Das hat auch damit zu tun, dass beinahe jede Kulturgruppe ihre eigene Verwendung entwickelte. In jedem Fall kann das Instrument auf eine reiche regionale Verbreitung verweisen. Höchst spannend ist die Verschneidung dieser regionalen Prägungen und Weiterentwicklung zu ganz neuen Ergebnissen. Das zeigt nicht zuletzt bereits seit Jahren das Internationale Akkordeonfestival das heuer zum 13. Mal vom 18. Februar bis 25. März an unterschiedlichen Orten in Wien stattfindet. Traditionell mit dabei und das gleich am Eröffnungsabend ist natürlich Otto Lechner - Virtuose und geistreicher Magier der blasebalggestützten Tasten.

Gemeinsam mit den Windhunden und im Doppelpack mit Vienna Balkan Groove bestreiten sie die Eröffnungsgala 1 in der Technischen Universität Wien und werden bei der Eröffnungsgala 2 am Folgetag mit der nicht minder feinen Konstellation aus den Neuen Wiener Concert Schrammeln und Renato Borghetti mit Band im Baumgartner Casino gefolgt. Attwenger spielen im Jazzclub Porgy\&Bess auf ebenso wie das Nuevo Tango Ensamble, Dobrek Bistro werden im Orpheum ordentlich einheizen und noch jede Menge andere musikalische Schmankerln stehen auf dem Programm.

Informationen: www.akkordeonfestival.at
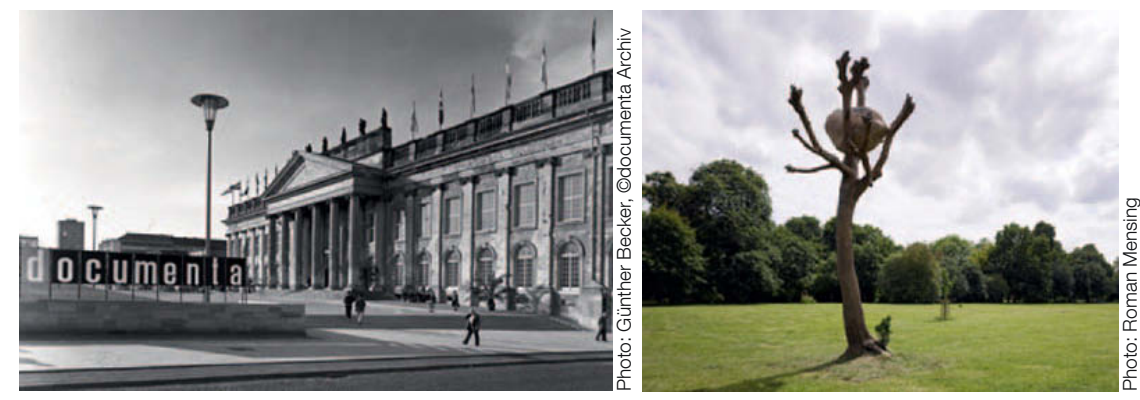

Herzstück der documenta ist das Fridericianum - Kunst findet in Kassel auch unter freiem Himmel statt.

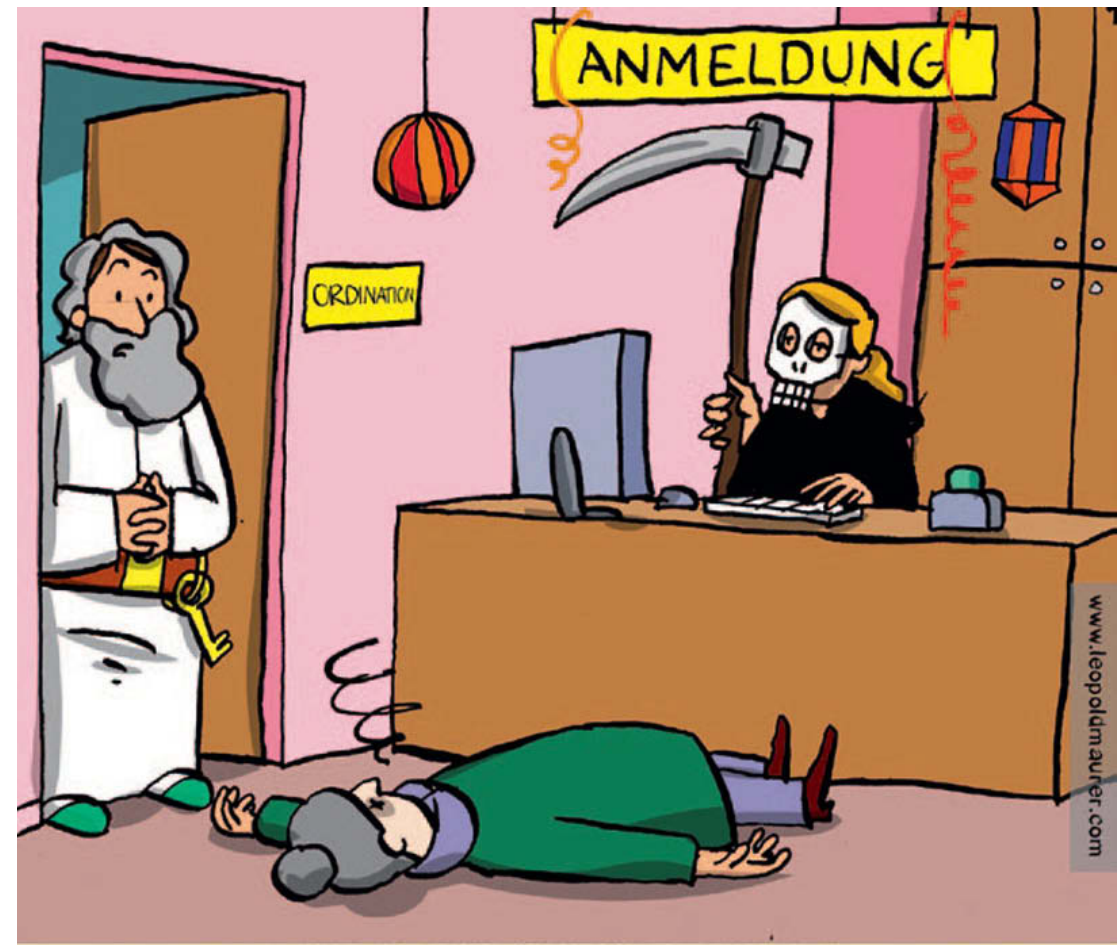

FASCHINGSKOSTÜME, DIE ÄRZTE UND SPRECHSTUNDENHILFEN VERMEIDEN SOLLTEN. 